\author{
Huseyin Gencay Keceli ${ }^{1 *}$, Serdar Yucel \\ Ozkan $^{2}$, Humerya Aydemir Turkal ${ }^{3}$ and \\ Tolga Fikret Tozum ${ }^{4}$ \\ ${ }^{1}$ Hacettepe University, Faculty of Dentistry, Department of \\ Periodontology, Ankara, TURKEY \\ ${ }^{2}$ Kirikkale University, Faculty of Dentistry, Periodontology \\ Department, Kirikkale, TURKEY \\ ${ }^{3}$ Gaziosmanpasa University, Faculty of Dentistry, \\ Department of Periodontology, Tokat, TURKEY \\ ${ }^{4}$ University of Illinois at Chicago, College of Dentistry, \\ Department of Periodontics, Chicago, Illinois, USA \\ Dates: Received: 04 March, 2015; Accepted: 19 \\ Case Report

\section{Management of Two-Wall Infra- Bony Defect with Platelet Rich Fibrin and Connective Tissue Graft Combination: A Case Report}

March, 2015; Published: 21 March, 2015

*Corresponding author: Huseyin Gencay

Keceli, Hacettepe University, Faculty of Dentistry,

Department of Periodontology, Ankara/TURKEY, Tel:

+90 312305 2217; Fax: +90 312310 4440; E-mail:

monsieur_gencay@yahoo.com

www.peertechz.com

Keywords: Infrabony defect; Gingival recession; Platelet-rich fibrin; Connective tissue graft

ISSN: 2394-8418

\section{Abbreviations}

(PRF) Platelet-rich Fibrin; (CTG) Connective Tissue Graft; (PDGF) Platelet-derived Growth Factor; (VEGF) Vascular Endothelial Growth Factor; (TGF) Transforming Growth Factor; (IGF) Insulin-like Growth Factor; (EGF) Epidermal Growth Factor and (bFGF) basic Fibroblast Growth Factor

\section{Background}

Alveolar bone destruction around the teeth is one of the most important signs of the progressive periodontal disease and may be the indicator of apical spreading degree of the disease. The bone defects formed in this way are defined as a deformity or concavity comprising the alveolar bone and may involve one or more teeth. Bony defect occurring in oblique direction alongside the root surface and having a base located in the apical of the alveolar crest is called 'infrabony' or 'intraosseous' defect. Although subgingival biofilm was defined as the main factor in development of periodontitis, excessive occlusal forces, tooth position and traumatic hygiene procedures could influence the severity and progression of periodontal disease and related infrabony defects [1]. Periodontal regeneration is described as complete restoration of lost tissues including alveolar bone, periodontal ligament and cementum to their original architecture and regarded as ultimate goal of the periodontal therapy [2-4] Based on the knowledge about current regenerative procedures involving use of various biomaterials in addition to autogenous and allogenic bone grafts offer a 'limited' potential toward achieving a complete periodontal regeneration and today, there is not any single material that can be considered as 'gold standard' in infrabony defect treatment.

With the increasing interest focused on accelerated wound healing and regeneration, platelet concentrates were introduced as the promoters of bone and soft tissue formation [5] and their encouraging effects have been exhibited in different periodontal [6] periapical [7] and peri-implant [8] surgeries. Platelet-rich fibrin (PRF) is the second generation platelet concentrate consisted of a completely autologous material including high-density fibrin network with leukocyte aggregate, and represents a slow release system (about the same concentration for 7-day duration) for growth factors such as platelet-derived growth factor (PDGF), vascular endothelial growth factor (VEGF), transforming growth factor (TGF), insulinlike growth factor (IGF), epidermal growth factor (EGF) and basic fibroblast growth factor (bFGF) $[9,10]$. PRF consists of various cytokines, structural glycoproteins and glycanic chains that reside within a gradually polymerizing fibrin matrix. This fibrin matrix is the actor component of the cicatricial capability of PRF and generation of PRF membrane, which has a specific physiologic conformation in order to support the course of wound healing, occurs with its gradual polymerization [11]. By virtue of these effects, PRF also accelerates haemostasis and has a supportive effect on immune system, cell migration and proliferation $[9,11,12]$. PRF preparation is a costeffective process with short chair-side duration [13] and does not need bovine thrombin and/or anticoagulant addition [14] further, the material does not require biochemical handling of blood and can be easily formed as a regenerative membrane. On the other hand, low 
available amount of the material and short handling duration can be counted as the main disadvantages. Use of PRF showed promising results in various periodontal surgical procedures such as treatment of infrabony and class II furcation defects and root coverage [15-17].

Treatment of wide infrabony defects with a deep dehiscence emphasizes the need to use of bone graft materials for the reconstruction of the interproximal infrabony defects may be effective in providing the adequate support to flap and the defect as well as accelerating bone regeneration in the healing process on the region. However, it is not always predictable to restore this type of deficiencies by using guided tissue regeneration and/or grafts. In the light of this information, being in search of such materials to meet this requirement seems to be substantive. The purpose of this case report is to describe two-stage treatment of a maxillary canine tooth having an infrabony defect accompanied with a deep dehiscence by using PRF-connective tissue graft combination.

\section{Case Report}

Patient demographics, treatment planning and phase I treatment

A 28-year-old man with no medical problems was referred to the Department of Periodontology showing purulent exudate formation and tooth mobility with deep periodontal destruction involving mesial, mid-buccal and slightly distal portion of the root in combination with $4 \mathrm{~mm}$ buccal recession in tooth \#23 (FDA classification) (Figure 1). Clinical probing depths and other baseline clinical variables were shown in Table 1. Other periodontal symptoms were bleeding on probing, pus formation, slight edema and redness with mild tactile and air blast sensitivity. As possible adjunctive etiologic factors, the tooth root was slightly inclined in labial direction and a premature contact was present. Radiographically, a significant radiolucency extending to the middle third of the mesial root surface was observed with a concomitant widening of the periodontal ligament space and loss of lamina dura in the surrounding alveolar bone (Figure 2).

Detailed oral hygiene instruction was given by emphasizing the importance of preventing traumatic tooth brushing and the initial periodontal treatment was performed. The other problems in the remaining dentition were treated. The patient was not voluntary to have an orthodontic treatment for correction of the slight labial position of the tooth. Relying on their influence on development and

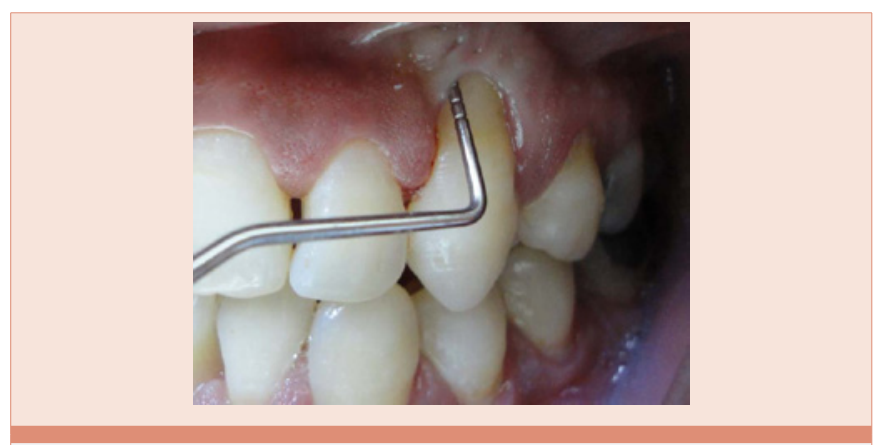

Figure 1: Pretreatment view of the maxillary left canine demonstrating deep periodontal pocket.

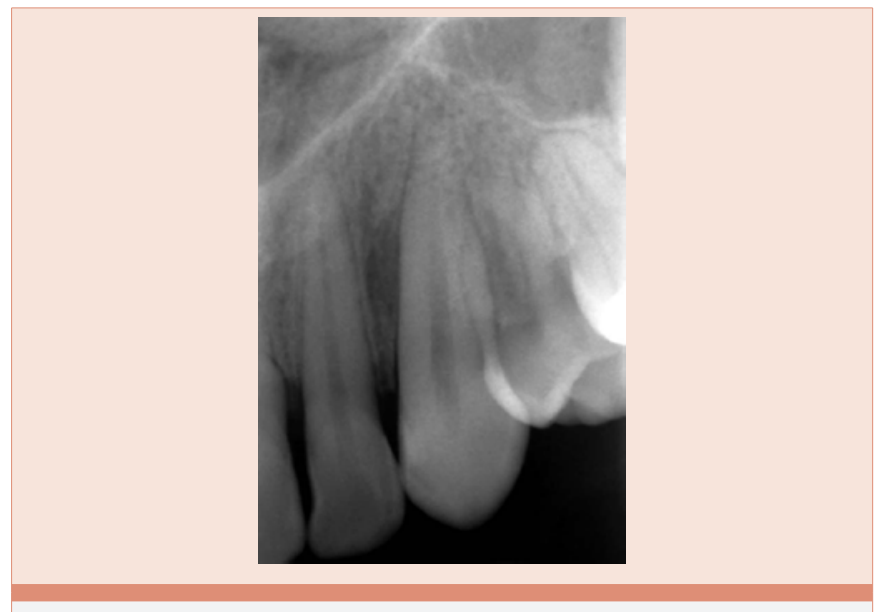

Figure 2: Pretreatment radiographic view. Supporting alveolar bone was lost in mesial side of the root.

progression of periodontal destruction, premature occlusal contacts of the entire dentition were removed by placing special emphasis on the tooth \#23 in this period. The patient was re-evaluated 3 weeks after phase I treatment in terms of being ready for the surgical phase.

\section{First surgery}

Surgical operation was performed by one of the authors (S.Y.O) as shown in Figure 3 after detailed explanation of the procedure was given to the patient an informed consent was signed. Following local anesthesia (Ultracaine D-S forte, Hoechst, Frankfurt, Germany), root planing was performed. Mucoperiosteal flap was elevated by using sulcular and vertical incisions. Following debridement, a two-wall circumferential defect beginning from mesial root surface and with a dehiscence extending nearly to the apex was detected (Distance from the cement-enamel junction (CEJ) to the bottom of the defect: $10 \mathrm{~mm}$, distance from CEJ to the most coronal extension of the bone crest: $7 \mathrm{~mm}$, intraosseous component of the defect: $3 \mathrm{~mm}$ ). No bone shaping was performed and infrabony part of the osseous defect was left empty. Just prior to CTG harvesting, $10 \mathrm{ml}$ venous blood was collected and taken to the chair-side centrifuge for PRF preparation. PRF was prepared simultaneous with CTG harvesting procedure in accordance with the method described by Choukroun et al. $[15,18]$ and demonstrated in Figure 4. Briefly, $10 \mathrm{ml}$ venous blood was collected from the antecubital vein into a sterile empty tube without anticoagulant and spun at $2700 \mathrm{rpm}$ for 12 minutes in a standard chair-side centrifuge. Immediately after centrifugation, acellular plasma at the top, red corpuscles at the bottom and fibrin clot that rich in platelets in the middle layer was procured. Acellular plasma was separated from the other fragments of the blood easily due to its liquid form. Then, red corpuscles base and yellow PRF clot was detached using a pair of sterile surgical scissors and dental tweezers. PRF clot was transferred to sterile gauze soaked in saline and slight compress was applied to extrude the serum ingredient. A stable, membrane formed fibrin was obtained in the end of the process.

CTG was removed from the palate by using single incision technique described by Hurzeler and Weng [19] and was surgically located over the coronal and $1 / 2$ middle third of the denuded root. 
Mild gauze compress was applied over the tissue during 5 minutes and stabilized with 6-0 absorbable sutures (Ethicon, Johnson \& Johnson, Somerville, NJ). Later on, prepared PRF gel was placed like a membrane over the remaining exposed root surface just below the CTG on the intended apical position. After application of slight pressure, overlying flap was sutured with 4-0 silk sutures (Dogsan, Trabzon, Turkey).

\section{Second surgery}

Except a partial necrosis in the marginal part of the CTG, slight hyperemia and edema the early wound healing was better than usual. After 6 months from the first surgery; clinical examination revealed shallow periodontal pockets and complete defect fill was observed according to the radiographic evaluation (Figure 5). However, $4 \mathrm{~mm}$ residual recession was still present in mid-buccal root surface (Figure 6). Therefore, it was decided to utilize a second surgery consisted of laterally positioned flap in combination with free gingival graft to treat the residual recession.

All steps of the second surgery are shown in Figure 7. Following anesthesia, the existing marginal tissue and a wedge of tissue apical to the margin was removed as the first step in correcting the recession defect. Thereafter, the gingival tissue belonging to the adjacent lateral incisor was reflected by full-thickness dissection. Although clinical photograph did not represent the defect fill clearly, following elevation, it was observed that the bone defect was completely filled, showing harmony with the pre-surgical pocket measurements, except its buccal component. The tissue flap was then moved laterally without tension to cover the defect and carefully secured with 4-0 silk sutures. Simultaneously, a free gingival graft was procured from the palate according to the previously described method to cover the exposed area at the donor site [20]. The graft was positioned at the cement-enamel junction and sutured around the lateral incisor. Interrupted sutures were then placed obliquely between the flap and the adjacent tissues.

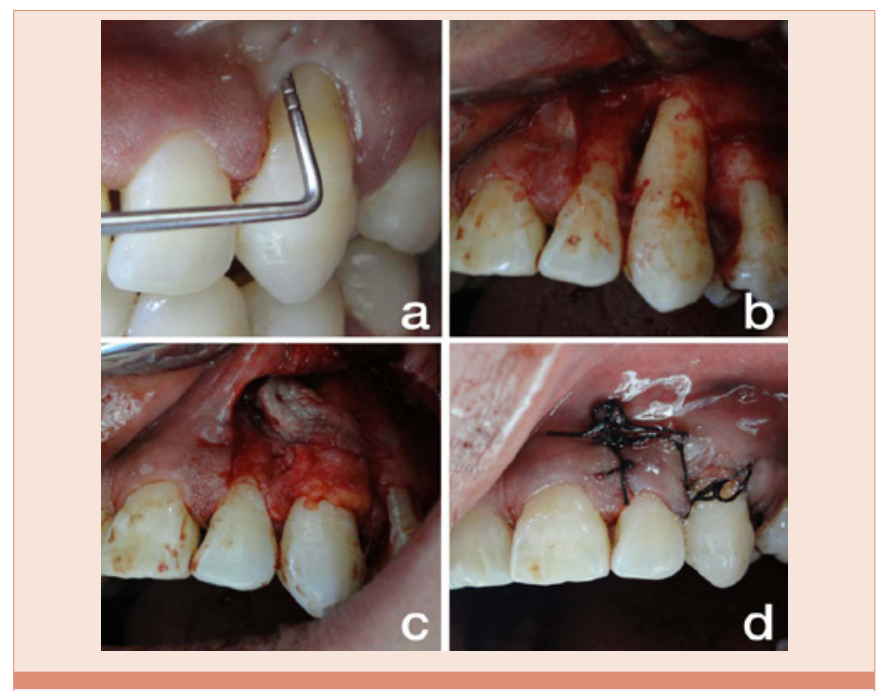

Figure 3: All steps of the first surgery.

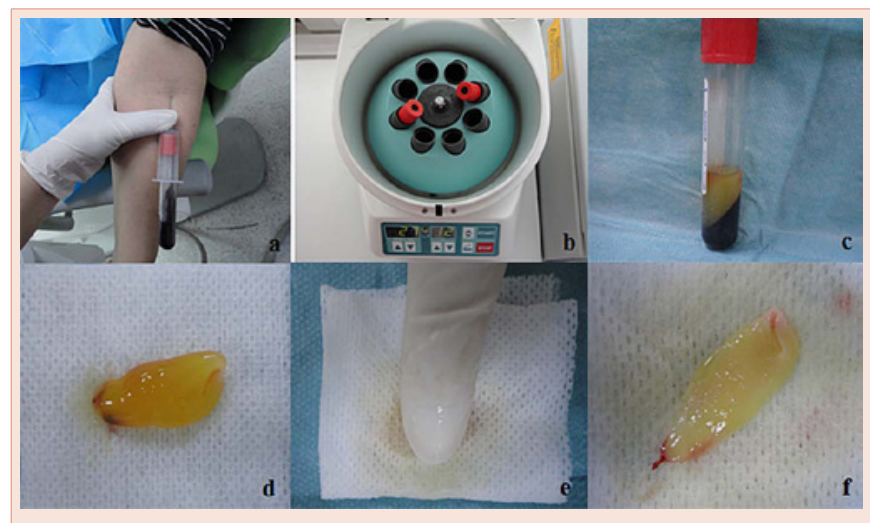

Figure 4: Preparation of PRF.

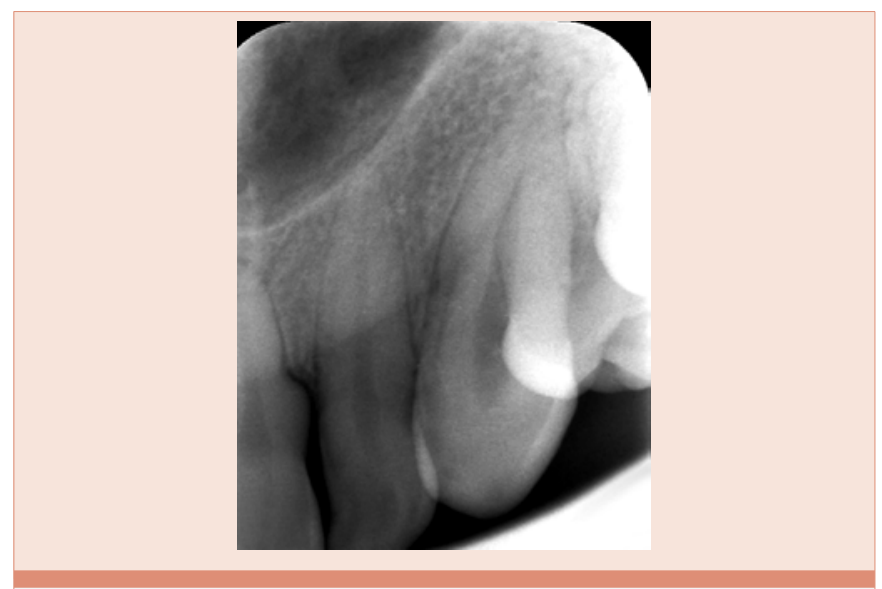

Figure 5: Periapical radiographic view 6 months after first surgery. Significant hard tissue fill was determined with no external root resorption.

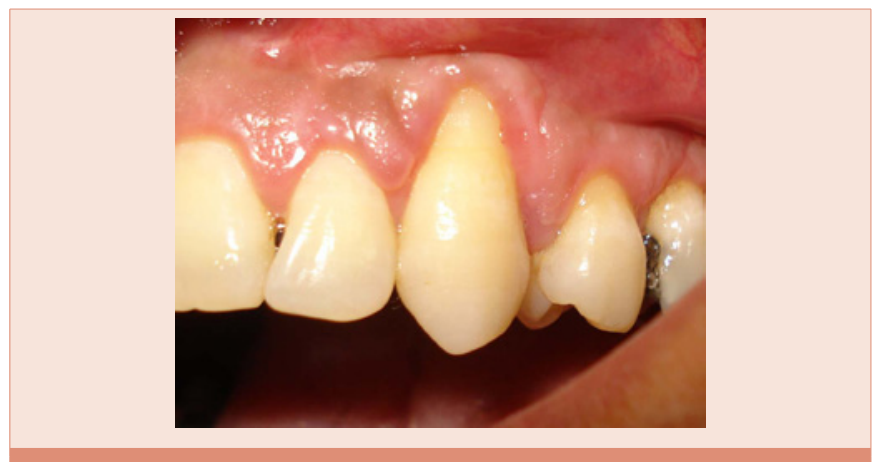

Figure 6: Clinical view 6 months after first surgery. $4 \mathrm{~mm}$ mid-buccal recession was still present.

\section{Postsurgical care and final evaluation}

Following both surgeries, chlorhexidine digluconate and nonsteroidal anti-inflammatory drugs were prescribed. The sutures were removed at 10 days. All periodontal clinical measurements and radiographic examination were repeated 6 and 12 months after second surgery, by the same clinician. Compared to baseline, 
significant improvements were detected at all periodontal clinical measurements (Table 1). Probing depths were reduced and gingival recession was completely covered. In the clinical examination, the gingiva was healthy with its pink and firm view and no bleeding on probing was detected at 12 months postsurgical examination. There was good color blending of the treated area with the adjacent soft tissue (Figure 8). Due to two-step surgical procedure, surgical scar was present and a minor recession (approximately $0.5 \mathrm{~mm}$ ) occurred in adjacent lateral and premolar teeth. However, no root hypersensitivity was detected. Radiographically, view of complete defect fill was maintained adjacent to the mesial root surface of the treated tooth and no root resorption or other complications were present (Figure 9). The patient was satisfied with outcomes of the treatment.

\section{Discussion}

The present report aimed to demonstrate the clinical efficacy of two-step procedure including placement of PRF in the treatment of a wide, two-wall infrabony defect extending apically in combination with deep dehiscence. As a result, treatment of an infrabony periodontal defect with flap surgery plus PRF and CTG demonstrated significant defect fill as demonstrated by clinical and radiographic

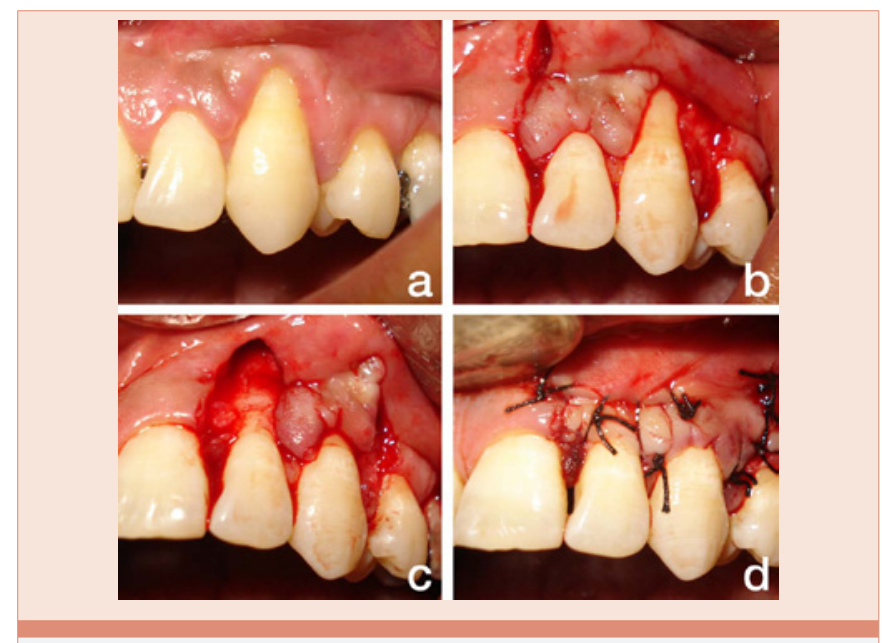

Figure 7: All steps of the second surgery.

Table 1: Periodontal clinical measurements.

\begin{tabular}{|c|c|c|c|c|c|c|c|c|c|c|c|}
\hline & \multirow{2}{*}{$\begin{array}{c}\text { PI } \\
(14)^{*}\end{array}$} & \multirow{2}{*}{$\begin{array}{c}\text { GI } \\
(14)^{*}\end{array}$} & \multicolumn{3}{|c|}{ PD } & \multicolumn{3}{|c|}{ CAL } & \multirow{2}{*}{$\begin{array}{l}\text { KT } \\
\text { mid }\end{array}$} & \multirow{2}{*}{$\begin{array}{l}\text { GR } \\
\text { mid }\end{array}$} & \multirow{2}{*}{ Mob } \\
\hline & & & mes & mid & dis & mes & mid & dis & & & \\
\hline $\begin{array}{l}\text { Baseline } \\
\text { (1st surgery) }\end{array}$ & 1.8 & 2.0 & 8 & 5 & 7 & 8 & 9 & 7 & 2 & 4 & 2 \\
\hline $\begin{array}{l}6 \text { months } \\
\text { (2nd surgery) }\end{array}$ & 0.3 & 0.5 & 2 & 2 & 3 & 2 & 6 & 3 & 2.5 & 4 & 0 \\
\hline 18 months & 0.5 & 1.0 & 3 & 3 & 3 & 3 & 3.5 & 3.5 & 3 & 0.5 & 0 \\
\hline
\end{tabular}

$\mathrm{Pl}=$ plaque index; $\mathrm{Gl}=$ gingival index; $\mathrm{PD}=$ probing depth; $\mathrm{AL}=$ attachment level; $\mathrm{KT}=$ keratinized tissue;

GR=gingival recession; mes=mesial; mid=mid-buccal; dis=distal; Mob=mobility; *indicates number of measurement sites

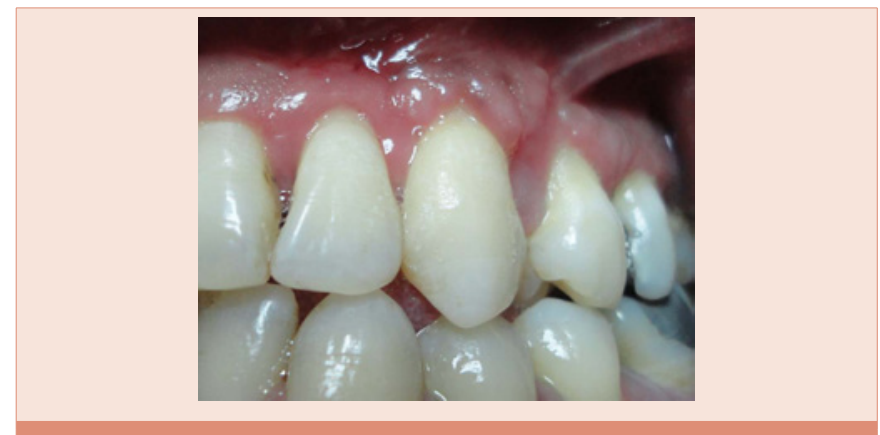

Figure 8: Clinical view one year after second surgery. Although slight recession and soft tissue deformity existed, almost complete root coverage was obtained with a healthy gingiva.

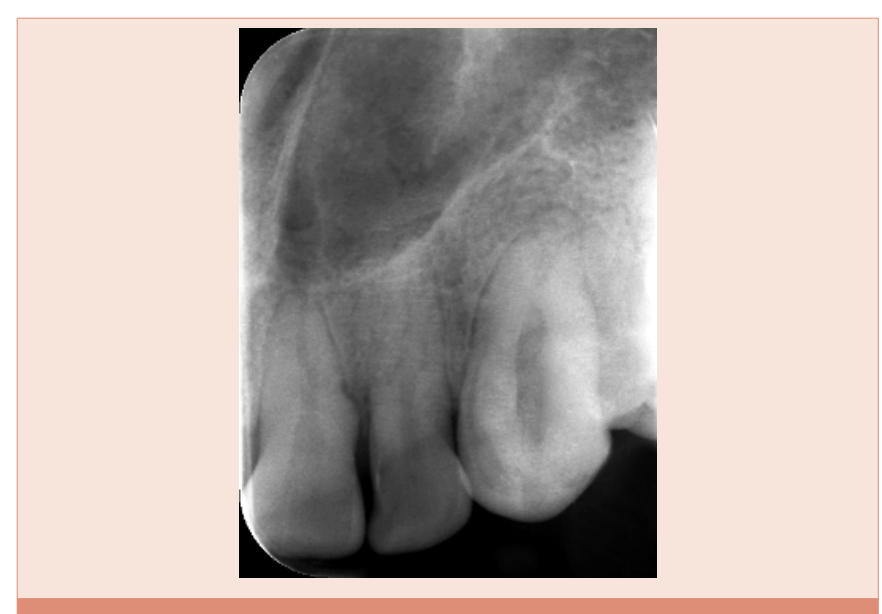

Figure 9: Periapical radiographic view one year after second surgery. Bone/ root resorption or any other complications were not detected.

examinations at one-year follow-up. However, residual mid buccal recession could be treated with a second-step mucogingival surgical procedure, laterally positioned flap-free gingival graft combination.

Two-wall infrabony defects do not provide the best three dimensional architecture for vascular and cellular bridging of the defect that originates from adjacent alveolar bone and periodontal ligament and especially in wide and non-containing two-wall defects the space maintenance cannot be provided satisfactorily by the defect walls for increasing the retention and minimizing the collapse of the materials $[21,22]$. Although the treated defect was partially supraalveolar and two-wall infrabony part was extending to the apex in combination with a buccal dehiscence, results of the exhibited twostep treatment revealed an obvious improvement of periodontal variables and this improvement might be associated with the positive effect of PRF to the cellular events during early healing period by its growth factor content. According to two randomized controlled clinical studies involving the evaluation of the effects of PRF in the surgical treatment of chronic periodontitis, enhanced healing of periodontal defect was found at sites treated with PRF than open flap debridement alone [23] and addition of PRF to porous hydroxyapatite graft increased observation of the regenerative effects [17]. In 2013, autologous PRF also added benefit to the clinical and radiographic outcomes including uneventful healing of the treated mandibular 
sites with type II furcation defects [23].

Many years before, the key role of space provision and wound stability in regenerative treatment was reported by some studies evaluating the guided tissue regeneration techniques and as verified, possibility of bone formation increases by providing space provision without rigorous interruption of the gingival connective tissue $[21,24,25]$. PRF was covered over the defect as a membrane in the first surgical step of the present case, and the role that was imputed to the PRF membrane was containing the infrabony part of the defect in the early phase of healing due to this principle. In addition, no osteoconductive graft material was placed due to excessive amount of defect depth and width; reduced number of bony walls and an accompanying buccal bone dehiscence. In this manner, direct contact of the growth factor-rich PRF gel with the bone resource surrounding the defect was provided which might have improved the clinical outcomes. As a result of treatment and 12 months follow-up, the defect was almost completely eliminated and satisfactory healing of periodontal tissues was observed. In the literature, there are also existing reports utilizing the required size PRF as filler into the infrabony defect and also placing the remaining part of the material to cover the same region as a barrier, successfully $[26,27]$.

CTG is one of the most predictable and frequently used technique for root coverage [28]. In 2005, Hirsch et al. [29] reported placement of CTG to prevent gingival recession following open flap debridement of periodontal defects and exhibited successful outcomes. However, harvesting a CTG in desired dimensions is not always possible due to anatomical properties of the donor site and the complication risk increases in accordance with the size of the harvested graft [30]. Except acellular dermal matrix allografts [31], no valid methods have been shown to eliminate/decrease the magnitude of the needed CTG. Addition of PRF to CTG might be thought as a new alternate to overcome this problem as exhibited in the present case.

The poor quality of the clinical and radiographic images, unclear view of the bone fill view in photograph of the re-entry surgery, scar formation and slight marginal recession on the gingival tissue of the adjacent teeth can be enumerated as the limitations of the present report. Although preparation of PRF gel is a cost-effective method, alternative regenerative techniques; e.g. utilization of enamel matrix derivatives in combination with soft tissue grafts, acellular dermal matrices with bone grafts, guided tissue membranes; are also valid for the management of such cases demonstrating combined bone and soft tissue deformity with thick soft tissue biotype $[32,33]$.

As a conclusion, PRF-CTG combination may be thought as a suitable alternative in the surgical reconstructive treatment of chronic periodontitis patients demonstrating wide, two-wall interproximal bone defects. This result may also support the idea of applying PRF like a regenerative membrane without any osteoconductive material successfully. However, long-term, randomized clinical trials are still needed for evidence.

\section{References}

1. Tugnait A, Clerehugh $V$ (2001) Gingival recession-its significance and management. J Dent 29:381-394.

2. Kao RT, Nares S, Reynolds MA (2015) Periodontal regeneration - intrabony defects: a systematic review from the AAP regeneration workshop. J Periodontol 86:77-104.

3. Maroo S, Murthy KR (2014) Treatment of periodontal intrabony defects using $\beta$-TCP alone or in combination with rhPDGF-BB: a randomized controlled clinical and radiographic study. Int J Periodontics Restorative Dent 34:841847.

4. Reynolds MA, Kao RT, Camargo PM, Caton JG, Clem DS, et al. (2015) Periodontal regeneration - intrabony defects: a consensus report from the AAP regeneration workshop. J Periodontol 86:105-107.

5. Tözüm TF, Demiralp B (2003) Platelet-rich plasma: a promising innovation in dentistry. J Can Dent Assoc 69:664.

6. Tözüm TF, Keçeli HG, Güncü GN, Hatipoğlu H, Sengün D (2005) Treatment of gingival recession: comparison of two techniques of subepithelial connective tissue graft. J Periodontol 76:1842-1848.

7. Demiralp B, Keçeli HG, Muhtaroğullar M, Serper A, Demiralp B, et al. (2004) Treatment of periapical inflammatory lesion with the combination of plateletrich plasma and tricalcium phosphate: a case report. J Endod 30:796-800.

8. Tözüm TF, Keçeli HG (2008) Treatment of peri-implant defect with modified sandwich bone augmentation. Case report and follow-up. N Y State Dent J 74:52-57.

9. Dohan Ehrenfest DM, Rasmusson L, Albrektsson T (2011) Classification of platelet concentrates: from pure platelet-rich plasma (P-PRP) to leucocyte and platelet rich fibrin (L-PRF). Trends Biotechnol 27:158-167.

10. DohanEhrenfest DM, Bielecki T, Del Corso M, Inchingolo F, Sammartino G (2010) Shedding light in the controversial terminology for platelet-rich products: Platelet-rich plasma (PRP), platelet-rich fibrin (PRF), plateletleukocyte gel (PLG), preparation rich in growth factors (PRGF), classification and commercialism. J Biomed Mater Res A 95:1280-1282.

11. DohanEhrenfest DM, Diss A, Odin G, Doglioli P, Hippolyte MP, et al. (2009) In vitro effects of Choukroun's PRF (platelet-rich fibrin) on human gingival fibroblasts, dermal prekeratinocytes, preadipocytes, and maxillofacial osteoblasts in primary cultures. Oral Surg Oral Med Oral Pathol Oral RadiolEndod 108:341-352.

12. Ghanaati S, Booms P, Orlowska A, Kubesch A, Lorenz J, et al. (2014) Advanced platelet-rich fibrin: a new concept for cell-based tissue engineering by means of inflammatory cells. J Oral Implantol 40:679-689.

13. DohanEhrenfest DM, Choukroun J, Diss A, Dohan SL, Dohan AJ, et al. (2006) Platelet-rich fibrin (PRF): a second-generation platelet concentrate. Part I: technological concepts and evolution. Oral Surg Oral Med Oral Pathol Oral RadiolEndod 101:e37-44.

14. Carroll RJ, Arnoczky SP, Graham S, O'Connell SM (2005) Characterization of autologous growth factors in Cascade platelet rich fibrin matrix (PRFM). Musculoskeletal Transplant Foundation. Edison, NJ, USA

15. Bajaj P, Pradeep AR, Agarwal E, Rao NS, Naik SB, et al. (2013) Comparative evaluation of autologous platelet-rich fibrin and platelet-rich plasma in the treatment of mandibular degree II furcation defects: a randomized controlled clinical trial. J Periodontal Res 48:573-581.

16. Tunalı M, Özdemir H, Arabacı T, Gürbüzer B, Pikdöken L, et al. (2015) Clinical evaluation of autologous platelet-rich fibrin in the treatment of multiple adjacent gingival recession defects: a 12-month study. Int J Periodontics Restorative Dent 35:105-114.

17. Pradeep AR, Bajaj P, Rao NS, Agarwal E, Naik SB (2012) Platelet-rich fibrin combined with a porous hydroxyapatite graft for the treatment of three-wall intrabony defects in chronic periodontitis: a randomized controlled clinical trial. J Periodontol 2012 Epub ahead of print.

18. Choukroun J, Adda F, Schoeffer C, Vervelle A (2000) PRF: an opportunity in perio-implantology (in French).Implantodontie 42:55-62.

19. Hurzeler MB, Weng D (1999) A single-incision technique to harvest subepithelial connective tissue grafts from the palate. Int $\mathrm{J}$ Periodontics Restorative Dent 19:279-287. 
20. Matter $\mathrm{J}$ (1982) Free gingival grafts for the treatment of gingival recession. $J$ ClinPeriodontol9:103-114.

21. Polimeni G, Xiropaidis AV, Wikesjö UM (2000) Biology and principles of periodontal wound healing/regeneration. Periodontol41:30-47.

22. Silness J, Loe H (1964) Periodontal Disease in Pregnancy. II. Correlation between oral hygiene and periodontal condition. ActaOdontolScand 22:121135.

23. Bajaj P, Pradeep AR, Agarwal E, Rao NS (2013) Comparative evaluation of autologous platelet-rich fibrin and platelet-rich plasma in the treatment of mandibular degree II furcation defects: a randomized controlled clinical trial. J Periodont Res 48:573-581.

24. Haney JM, Nilve'us RE, McMillan PJ, Wikesjö UM (1993) Periodontal repair in dogs: expanded polytetrafluoroethylene barrier membranes support wound stabilization and enhance bone regeneration. J Periodontol 64:883-890.

25. Sigurdsson TJ, Hardwick R, Bogle GC, Wikesjö UM (1994) Periodontal repair in dogs: space provision by reinforced ePTFE membranes enhances bone and cementum regeneration in large supraalveolar defects. J Periodontol 65:350-356.

26. Thorat M, Pradeep AR, Pallavi B (2011) Clinical effect of autologous plateletrich fibrin in the treatment of intrabony defects: A controlled clinical trial. $\mathrm{J}$ ClinPeriodontol 38:925-932.

27. Pradeep AR, Rao NS, Agarwal E, Bajaj P, Kumari M, et al. (2012) Comparative evaluation of autologous platelet-rich fibrin and platelet-rich plasma in the treatment of 3-wall intrabony defects in chronic periodontitis: A randomized controlled clinical trial. J Periodontol 83:1499-1507.

28. Keceli HG, Sengun D, Berberoğlu A, Karabulut E (2008) Use of platelet gel with connective tissue grafts for root coverage: a randomized-controlled trial. J ClinPeriodontol 35:255-262.

29. Hirsch A, Brayer L, Shapira L, Goldstein M (2004) Prevention of gingival recession following flap debridement surgery by subepithelial connective tissue graft: Consecutive case series. J Periodontol 75:757-761.

30. Reiser GM, Bruno JF, Mahan PE, Larkin LH (1996) The subepithelial connective tissue graft palatal donor site: Anatomic consideration for surgeons. Int J Periodontics Restorative Dent 16:131-137.

31. Ahmedbeyli C, Ipci ŞD, Cakar G, Kuru BE, Yılmaz S (2014) Clinical evaluation of coronally advanced flap with or without acellular dermal matrix graft on complete defect coverage for the treatment of multiple gingival recessions with thin tissue biotype. J ClinPeriodontol 41:303-310.

32. Miron RJ, Wei L, Bosshardt DD, Buser D, Sculean A, et al. (2014) Effects of enamel matrix proteins in combination with a bovine-derived natural bone mineral for the repair of bone defects. Clin Oral Investig 18:471-478.

33. Mitani A, Takasu H, Horibe T, Furuta H, Nagasaka T, et al. (2015) Five-year clinical results for treatment of intrabony defects with EMD, guided tissue regeneration and open-flap debridement: a case series. J Periodontal Res 50:123-130.

Copyright: (c) 2015 Keceli HG, et al. This is an open-access article distributed under the terms of the Creative Commons Attribution License, which permits unrestricted use, distribution, and reproduction in any medium, provided the original author and source are credited. 